\title{
Notas sobre el tema Chile en América Latina
}

\author{
RODRIGO BAÑO
}

Uno de los problemas más recurrentes es el de la integración latinoamericana. Prácticamente desde que los países de la región se proclaman tales, y aún antes, ya está planteado el problema de la unidad o dispersión de quiénes la componen. Tema permanente que siempre presenta nuevas formas de expresión ante las cambiantes situaciones históricas. En la actualidad pareciera volver a plantearse con fuerza en términos de estrategias para enfrentar las transformaciones a escala mundial, donde destaca la particular situación de Chile, que pareciera orientarse más hacia fuera de América Latina que hacia su integración con ésta. No es la primera vez que un país en esta zona amenaza con despedirse de la región, otros también, en distintos momentos históricos, plantearon esta despedida; alguna vez fue Argentina, otra vez fue Brasil. Quizás la diferencia sea que ahora parecieran primar los factores externos más que los internos, puesto que todo pareciera tender a ser definido en términos de requerimientos de la globalización. Esto tanto para quiénes en Chile buscan formas de inserción autónoma en la economía mundial, como para quiénes lanzan propuestas de integración mirando con envidia el éxito de la Unión Europea.

Poco a poco se han ido decantando los rasgos que permiten caracterizar el período actual como globalización, esto es: revolución científico tecnológica; hegemonía de modelos de capitalismo económico y democracia política; predominio militar y estratégico de Estados Unidos; transnacionalización y multipolaridad económica; creciente crisis de los estados nacionales. Esta gruesa caracterización de la época es lo que permite, tanto el planteamiento de la regionalización como estrategia económica defensiva para América Latina, como la alternativa de distanciamiento regional para buscar como país independiente las formas de inserción en la economía mundial que permitan obtener las mejores ventajas comparativas y disminuir los riesgos.

En cuanto a las estrategias de regionalización, como se sabe éstas tienen larga data $y$, aunque actualmente se nutren de las expectativas que abre una integración exitosa como la europea, mantienen ciertos rasgos comunes que suelen definir dos opciones bastante nítidas: aquellas impulsadas por Estados Unidos, que natural- 
mente las hegemoniza; y aquellas que los países iberoamericanos intentan realizar con independencia de esa gran potencia. El panamericanismo, impulsado por Estados Unidos y planteado desde hace largo tiempo en iniciativas como la OEA en el plano político, o como la Alianza para el Progreso en el plano económico, tiene actualmente un fuerte desarrollo en el inicial NAFTA, que pretende expandirse a la totalidad de la región mediante su creciente integración a un tratado de libre comercio, según la Iniciativa para América de Busch. El latinoamericanismo, por su parte, presenta también en la actualidad algunas iniciativas de integración económica, como el Pacto Andino, que languidece ante los problemas por que pasan sus principales componentes, el renovado Mercado Común Centroamericano, y el Mercosur, que aparece con mayor dinamismo. A la vez, en el campo político, el Grupo Contadora, inicialmente formado por México, Colombia, Venezuela y Panamá, para enfrentar los conflictos centroamericanos, en veinte años se ha transformado en el Grupo de Río en el que participan todos los países sudamericanos más un representante de Centroamérica y uno del Caribe. La preocupación principal de este grupo ha sido la defensa de la democracia política en los países de la región, pero su actuación ha sido bastante tímida frente a los problemas presentados en Perú, Haití, Surinam y Guatemala. No obstante, últimamente pareciera estar derivando su preocupación hacia temas económicos.

Esta rápida mirada permite constatar que no es posible hablar de muchos avances en proyectos de integración regional. Incluso se podría señalar que el inicial impulso de Mercosur, que prometía transformarse en una especie de núcleo de integración, se ha visto frenado por los problemas experimentados por su mayores componentes: Brasil y Argentina. Si persisten las iniciativas integradoras, éstas adquieren cada vez más nítidamente ese carácter de estrategias económicas defensivas frente a los problemas que acarrea la denominada globalización. Situación que se manifiesta en la proliferación de tratados de tipo bilateral impulsados por intereses económicos.

En el campo propiamente político, la debilidad de los estados nacionales en América Latina ha sido creciente. Esto no sólo debido a la progresiva pérdida de autonomía que han experimentado en cuanto a la dirección de su economía, sino que también por problemas de desintegración interna bastante notorios. Ciertos fenómenos de multiculturalismo han afectado bastante a algunos países de la región, especialmente en cuanto a la emergencia de movimientos de indigenismo difíciles de resolver. A ello se suma en algunos casos problemas de migración que alteran la integración de las comunidades nacionales. Otro factor que influye poderosamente al debilitamiento de la integración nacional está dado por la agudización del corte social que parecieran estar produciendo la progresiva implantación del modelo económico neoliberal. Finalmente, las políticas privatizadoras y el retrai- 
miento del Estado en su función de protección social, colaboran eficazmente en un creciente desinterés y apatía política, que naturalmente son un poderoso factor en la debilidad de los estados nacionales.

Naturalmente, lo anterior se relaciona muy estrechamente con un debilitamiento de los sujetos sociales y políticos en cada país, y su reemplazo por aparatos tecnocráticos o liderazgos personales según las condiciones particulares de cada uno. Organizaciones sociales y partidos políticos débiles implican grandes dificultades para la elaboración de proyectos de carácter nacional y más aún de integración regional.

Podrá parecer extraño plantear como problema para la integración regional la debilidad de los estados nacionales y de los sujetos sociales y políticos del mismo carácter. Sin embargo, es posible sostener que estas debilidades pueden favorecer la integración en términos de alguna especie de panamericanismo en torno a la potencia norteamericana, pero difícilmente lo harán en cuanto proyecto latinoamericano independiente de tal potencia, especialmente si se piensa en términos de proyecto político y no sólo coyunturalmente por conveniencias económicas inmediatas.

$\mathrm{Al}$ respecto parece adecuado citar a un autor generalmente recibido con antipatía, pero que no por eso deja de acertar al señalar un elemento definitorio central en la política. Se trata de Schmitt, quién en "El concepto de lo político" va a poner énfasis en que las categorías que definen lo político tienen carácter relacional y apuntan a la agrupación en términos de amigos y enemigos, entendidos como amigos y enemigos públicos y no meramente personales. Es evidente que, más allá de las exageraciones que se hagan de esta proposición, y aceptando todos los matices, aclaraciones y consideraciones que pueden plantearse, este concepto de lo político apunta a un elemento central que está presente en la constitución de todas las comunidades políticas. Para el asunto que aquí interesa, resulta pertinente considerar que no existe posibilidad de un proyecto de integración iberoamericana si no existe algún principio que logre articular a la región en términos de "amigos" frente a aquello que es definido como lo otro, como "enemigo". Demás está decir que no se está pensando en términos de enfrentamiento bélico, como también está demás recordar que el "nosotros" siempre implica una diferenciación de los "otros" de diversa intensidad.

Sabido es que un imperio sólo incorpora a otras poblaciones y territorios en la medida que ello le resulta conveniente para su defensa frente a algún antagonista o porque corresponde a su proyecto de dominación. Es más, la consigna de "dividir para reinar" se ha aplicado históricamente con singular empeño. Es así como Francia ayudará a la independencia de EEUU para debilitar a Inglaterra, de la misma manera que Inglaterra ayudará a la independencia de los países latinoamericanos para debilitar a España. Por otra parte, siempre será el interés de las potencias pro- 
curar mantener desintegrados nuevos estados, tratando siempre de dificultar su integración en unidades más amplias. Así ocurre en distintos momentos con los países que se forman con la desintegración del Imperio Otomano, Yugoslavia, los árabes, África y América Latina. Los ejemplos sobran.

Dadas esas condiciones, las posibilidades de integración regional sólo pueden provenir del interior de los países que pretendan integrarse, y es ahí donde cuentan estas debilidades de los estados nacionales y de sujetos sociales y políticos en ellos. Realmente sólo movimientos políticos internos pueden generar tales proyectos en la medida que ensayen una definición más amplia de comunidad política que les permita enfrentar las dificultades nacionales frente a la dominación externa. Al respecto conviene recordar que la teoría de la dependencia, que todavía pareciera conservar su potencial explicativo, señala que las bases de la dominación externa, en países que no son colonias políticas, se encuentran en la dominación interna que controla tal vinculación.

Históricamente, y más allá de los cuestionamientos que se puedan hacer a las orientaciones y conducciones planteadas, los momentos de mayor movilización en términos de integración política se corresponden con aquellos en que organizaciones políticas nacionales plantearon articulaciones de carácter regional bajo las banderas del antiimperialismo. Recuérdese al efecto el APRA del Perú y la coordinación partidaria antiimperialista en que participaron el MNR boliviano, $A D$ venezolano y el PS chileno, en la primera mitad del siglo XX; y la OLAS y los movimientos de liberación de la segunda mitad del mismo siglo.

Podrá señalarse con razón que los tiempos actuales establecen condiciones en que no puede plantearse tal tipo de orientaciones políticas, sin embargo también está claro que sin planteamientos coherentes que permitan identificar "lo otro", frente a lo cual se definen las afinidades de los países latinoamericanos, resulta bastante difícil proyectar algún tipo de integración regional no subordinado a la potencia hemisférica. La recurrente apelación a una supuesta globalización, que borraría las fronteras de los estados nacionales, pareciera ignorar que, no obstante las crisis y transformaciones de éstos, la realidad de los estados nacionales es innegable y que la política sigue reconociendo en ellos sus sujetos fundamentales. El orden mundial es un orden estatal y lo más probable es que lo siga siendo por mucho tiempo, pues la creciente diferenciación necesita de una multiplicación de regulaciones legales que sólo el respaldo coactivo puede garantizar.

Es en el tema general de la integración o desintegración latinoamericana donde se plantea la interrogación de qué es lo que pasa con Chile en América Latina. "Chile en América Latina" es una afirmación y es una pregunta, pues, si es innega- 
ble que por geografía, historia y cultura está en esta región, son visibles las tendencias a aislarlo de ella en cuanto a sus proyecciones futuras. Más allá de nostálgicas referencias a su vinculación regional, lo cierto es que en las actuales circunstancias no pareciera haber una orientación integradora: no sólo las relaciones económicas se buscan en los grandes centros de desarrollo capitalista, sino que las relaciones políticas con otros países de iberoamérica, especialmente los vecinos, se tornan difíciles.

Por cierto que este creciente aislamiento regional no es casual, sino que se corresponde con el predominio de orientaciones políticas que se niegan precisamente a ser tales orientaciones y que se empeñan en asumir un creciente pragmatismo, que tiende a transformar la política en administración de lo que se entiende como designios ineludibles del destino. En la medida que los indicadores que se privilegian para medir el desempeño se muestran favorables, naturalmente se insiste en una práctica que aparece como justificada desde el punto de vista de la lógica técnica. Nuevamente, como tantas otras veces, se desatiende el problema político para darle prioridad a lo que aparece como exigencias inmediatas de la economía, enajenando la discusión y decisión en términos de valores y perdiendo incluso la posibilidad de diseñar un proyecto económico de más largo plazo y mayor seguridad que efectivamente corresponda a lo que socialmente se desea como vida buena. No es ocioso al respecto recordar cómo el discurso sobre socialismo, inicialmente un proyecto de liberación humana, se transformó en un discurso que sólo pretendía justificarlo en cuanto su superioridad técnica para lograr el desarrollo económico... y los "socialismos reales" fueron muy eficaces inicialmente para lograr tal tipo de desarrollo.

El orientar este número de la Revista de Sociología al tema "Chile en América Latina", tiene por objetivo participar en las discusiones que en la actualidad se abren, sin por ello pretender plantear líneas u orientaciones al respecto. Es más, los artículos que aquí se presentan apuntan más a presentar un cierto diagnóstico de la situación latinoamericana y de la condición de Chile en ella, como una forma de aportar ciertas informaciones básicas para la comprensión del tema. 